\title{
The telomere of human chromosome $1 p$ contains at least two independent autosomal dominant congenital cataract genes
}

\author{
J D McKay, B Patterson, J E Craig, I M Russell-Eggitt, M G Wirth, K P Burdon, A W Hewitt, \\ A C Cohn, Y Kerdraon, D A Mackey
}

Br J Ophthalmol 2005;89:831-834. doi: 10.1136/bjo.2004.058495

\begin{abstract}
Aims: Multiple genetic causes of congenital cataract have been identified, both as a component of syndromes and in families that present with isolated congenital cataract. Linkage analysis was used to map the genetic locus in a six generation Australian family presenting with total congenital cataract.

Methods: Microsatellite markers located across all known autosomal dominant congenital cataract loci were genotyped in all recruited family members of the Tasmanian family. Both two point and multipoint linkage analysis were used to assess each locus under an autosomal dominant model.

Results: Significant linkage was detected at the telomere of the $p$ arm of chromosome 1, with a maximum two point LOD of 4.21 at marker D1S507, a maximum multipoint exact LOD of 5.44, and an estimated location score of 5.61 at marker D1S507. Haplotype analysis places the gene inside a critical region between D1S228 and D1S199, a distance of approximately 6 megabases. The candidate gene PAX7 residing within the critical interval was excluded by direct sequencing in affected individuals.

Conclusion: This is the third report of congenital cataract linkage to 1 ptel. The critical region as defined by the shared haplotype in this family is clearly centromeric from the Volkmann cataract locus identified through study of a Danish family, indicating that two genes causing autosomal dominant congenital cataract map to the telomeric region of chromosome $1 \mathrm{p}$.
\end{abstract}

\footnotetext{
A
} utosomal dominant congenital cataract (ADCC) is one of the most common causes of childhood blindness. The disorder is clinically heterogeneous, with the presentation of cataract varying considerably between families and even between individuals carrying identical mutations. ${ }^{1}$ Genetically, ADCC is also highly heterogeneous, but within a given family congenital cataract tends to be monogenic with high penetrance. Autosomal dominant inheritance is the most common form, although recessive forms have been described. ${ }^{2}$ Mutations causing cataracts have been identified in genes from diverse classes including membrane proteins, cytoskeletal proteins, and transcription factors. $^{3-6}$ Causative genes remain to be identified at further mapped loci indicating that further genetic heterogeneity exists. $^{7-12}$

Here, we use linkage analysis to map the ADCC gene segregating in a large family from the Australian island state of Tasmania. Using linkage and haplotype based approaches we have shown that this locus is independent of the described Volkmann-type congenital cataract locus previously mapped to this region.

\section{METHODS}

We identified a six generation family originating from the Australian island state of Tasmania with ADCC. ${ }^{13}$ This is one of several families previously screened for mutations in crystallin genes. ${ }^{14}$ Family members were recruited with written informed consent obtained from all participating individuals or their guardians. DNA was available from 16 members of the four most recent generations and was extracted from whole blood or buccal mucosal swabs using the PureGene DNA Isolation Kit (Gentra Systems). Ethics approval for this study was obtained from the human research ethics committees of the Royal Children's Hospital, Melbourne, the Royal Victorian Eye and Ear Hospital, Melbourne, and the University of Tasmania, Hobart, and we adhered to the tenets of the Declaration of Helsinki.

\section{Genotyping}

Forward primers for each marker were labelled with fluorescent dyes to allow detection of polymerase chain reaction (PCR) fragments on an ABI PRISM 310 genetic analyser (Applied Biosystems). Primer sequences and PCR conditions are available from the Genome Database (www.gdb.org). Microsatellites were genotyped by the Australian Genome Research facility in or near all known ADCC loci, including: D1S468-DiS2660 (lptel) and D1S252D1S498 (1q21), D2S2358-D2S325 (CRYG), D3S1569D3S1593 (BFSP2), D10S192-D10S597 (PITX3), D11S898D11S4090 (CRYAB), D12S83-D12S313 (MIP), D13S1236D13S175 (CX46), D15S117-D15S1033 (15q21-q22), D16S3066-D16S515 (HSF4), D17S1857-D17S1824 (CRYBAI), D17S1847-D17S836 (17q24), D17S849-D17S831 (17p13), D20S115-D20S871 (20p12-q12), D21S1255-D21S266 (CRYAA), D22S315-D22S1154 (CRYB). Additional microsatellites located on the 1p telomere were genotyped: D1S214, DiS450, DiS244, D1S2667, DiS489, DiS228, D1S507, D1S2728, D1S436, D1S2644, D1S199.

\section{Linkage analysis}

The analysis model assumed a high genetic risk, autosomal dominant model. The disease gene frequency was assumed to be rare at 0.001 and genotype penetrances of aa 0.001 Aa 0.95 AA 0.95. Two point LOD scores were calculated using MLINK. Multipoint LOD scores were calculated using approximate location scores using the SimWalk2 program $^{15}$ and exact LOD scores using the Vitesse program. ${ }^{16}$ Analysis using Vitesse was limited to three markers (D1S507-D1S2728-D1S2644)

Abbreviations: $A D C C$, autosomal dominant congenital cataract; $P C R$, polymerase chain reaction; SNP, single nucleotide polymorphism 


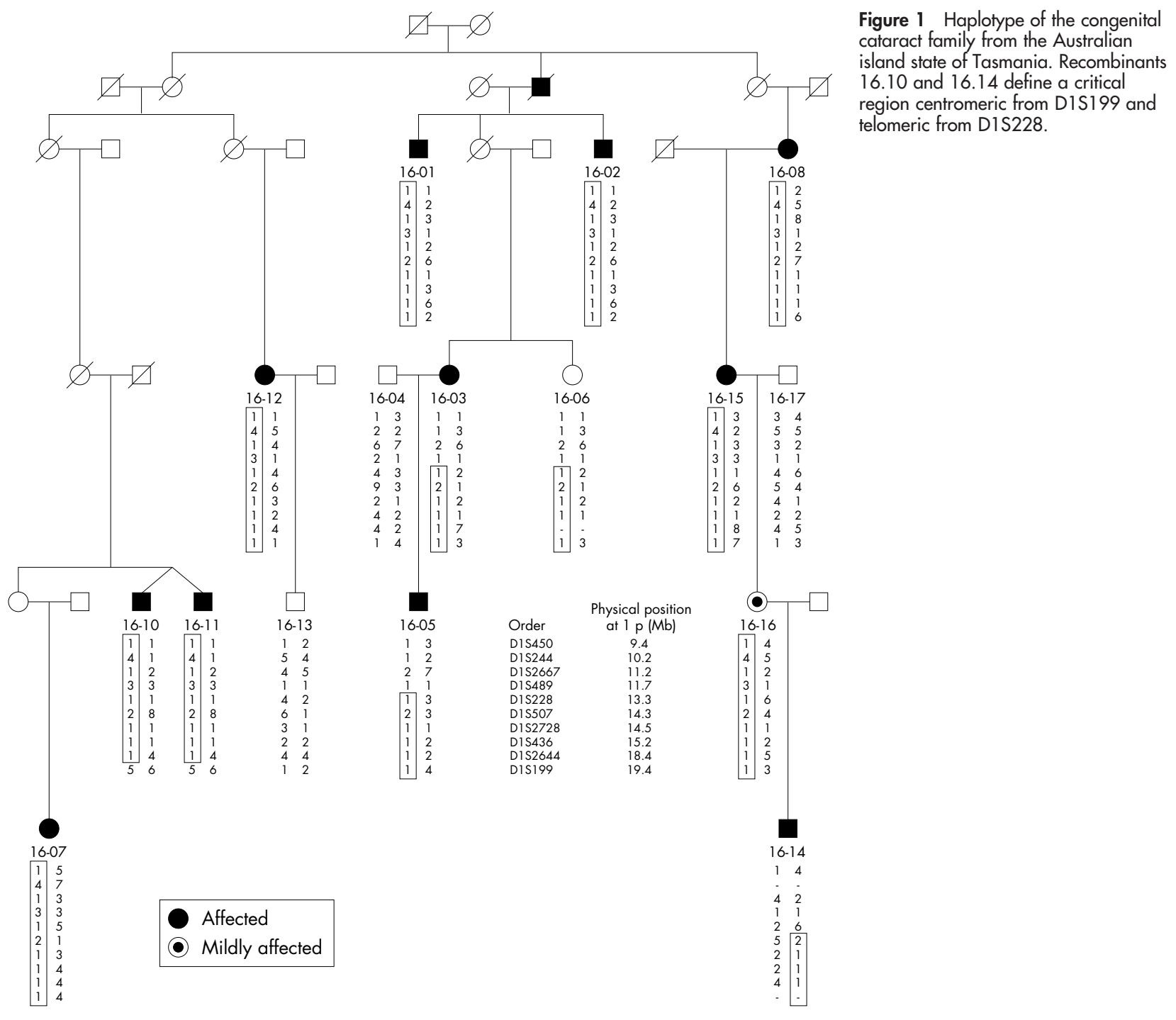

because of the size of the kindred. The genetic positions of the markers were taken from the Decode ${ }^{17}$ and Marshfield ${ }^{18}$ genetic maps and the marker order confirmed using their physical position in the human genome (genome.ucsc.edu/ cgi-bin/hgGateway). Allele frequencies were taken from the genome database. Individuals 16.10 and 16.11 are monozygotic twins and hence only patient 16.10 was included in the linkage analysis.

\section{Re-sequencing of PAX7 in affected patients}

The coding region of the candidate gene PAX7 was resequenced in two affected patients as well as one unaffected individual. Primers were designed to amplify each of the eight identified exons (primers available on request) from genomic DNA. Amplified products were purified using spin columns (MoBio) and sequencing was performed on an ABI PRISM 310 genetic analyser (Applied Biosystems).

\section{RESULTS}

Clinical notes from two patients in the Tasmanian pedigree describe the phenotype as a complete cataract (16.05 and 16.14) although most affected members are elderly and aphakic, with no preoperative clinical notes available. The median age of diagnosis was less than 1 year (range birth to 9 years), however most were diagnosed shortly after birth and the mean age of cataract surgery was 3 years 4 months (range 0-9 years). Twelve of the 13 patients had bilateral cataract surgery and were aphakic (eight had acuities $<6 / 60$ and four had acuities 6/19-6/60), corrected with spectacles. There is one affected member (16.16, fig 1) who is an obligate carrier but has a relatively mild phenotype, phakic with good vision (6/6-1 6/7.5+2) but not available for slit lamp examination. Eleven of 12 of the aphakic individuals had nystagmus. Two individuals had exotropia (16.02, 16.08) and four esotropia (16.03, 16.06, 16.07, 16.11). Four individuals had bilateral aphakic glaucoma (16.03, 16.05, $16.08,16.15)$. No other ocular or systemic abnormalities were noted.

Linkage analysis using the microsatellite markers genotyped across the known cataract loci detected significant linkage at the telomere of chromosome lp. Two point LOD scores of greater than three were achieved at markers DIS507 and D1S2644, with LODs of 4.21 and $3.23(\theta=0)$ respectively (table 1). Multipoint analysis achieved maximum location scores $^{15}$ and LOD scores ${ }^{16}$ of 5.61 and 5.44 respectively (table 1). Combined, these results indicate significant linkage to this region making it highly probable that the gene segregating in this family maps to this locus. All other regions tested failed to reach significance or were inconsistent with linkage (data not shown). 


\begin{tabular}{|c|c|c|c|c|c|c|c|}
\hline & MLINK & LOD score & & & & SimWalk & Vitesse \\
\hline & 0 & 0.1 & 0.2 & 0.3 & 0.4 & Location & \\
\hline $\begin{array}{l}\theta \text { value } \\
\text { D1S2660 }\end{array}$ & -0.19 & 1.14 & 0.85 & 0.5 & 0.2 & $\begin{array}{l}\text { score } \\
0.021\end{array}$ & LOD score \\
\hline D1S214 & -4.68 & -1.64 & -0.78 & -0.36 & -0.13 & -2.84 & \\
\hline DIS450 & 1.09 & 0.86 & 0.59 & 0.34 & 0.15 & -2.02 & \\
\hline D1S244 & -0.11 & 1.11 & 0.82 & 0.47 & 0.19 & -2 & \\
\hline D1S2667 & -2.23 & 1 & 0.91 & 0.61 & 0.29 & -1.79 & \\
\hline D1S489 & -3.67 & -0.48 & -0.22 & -0.13 & -0.07 & -1.69 & \\
\hline D1S228 & -0.54 & 0.78 & 0.52 & 0.24 & 0.06 & 2.58 & \\
\hline DIS507 & 4.21 & 3.34 & 2.43 & 1.51 & 0.68 & 5.62 & 5.44 \\
\hline DIS2728 & 1.47 & 1.06 & 0.69 & 0.39 & 0.16 & 5.62 & 5.44 \\
\hline DIS436 & 1.15 & 0.79 & 0.48 & 0.25 & 0.09 & 5.55 & \\
\hline DIS2644 & 3.24 & 2.51 & 1.77 & 1.07 & 0.47 & 5.32 & 5.27 \\
\hline DIS199 & -0.17 & 1.15 & 0.86 & 0.52 & 0.22 & 2.63 & \\
\hline
\end{tabular}

The inferred haplotypes across lpter are displayed in figure 1. Two informative recombinants, 16.10 and 16.14, define a critical region between centromeric marker D1S199 and telomeric marker D1S228. The physical location of these markers indicated that the region containing the gene spans a physical distance of approximately 6 megabases $(\mathrm{Mb})$.

Eiberg et $a l^{7}$ studied a large Danish pedigree affected with Volkmann-type congenital cataract to map the gene for this disorder to the interval between the 1p telomere and D1S214. In the Tasmanian family the recombinants 16.14 and descendants of 16.20 all indicate that the gene segregating in this family is located at a position $6 \mathrm{Mb}$ telomeric to D1S214 (fig 2). As there is $6 \mathrm{Mb}$ between the two critical regions defined by these studies, it is likely that the genes in the Tasmanian and Danish pedigrees are not allelic and provides strong evidence that there are at least two genes predisposing to ADCC on the telomeric region of chromosome lp.

The $P A X$ transcription factors have been implicated in ocular development and congenital cataract. ${ }^{19}$ The presence of

$\begin{array}{cccc}\begin{array}{c}\text { Danish } \\ \text { Volkmann }\end{array} & \text { Bristish } & \text { This } & \text { posterior } \\ \text { polar } & \text { study } & \text { congenital } \\ \text { Eiberg et al } & \begin{array}{c}\text { pola } \\ \text { lonides et } a l^{8}\end{array} & & \begin{array}{c}\text { glaucoma } \\ \text { Akarsu et al }\end{array}\end{array}$

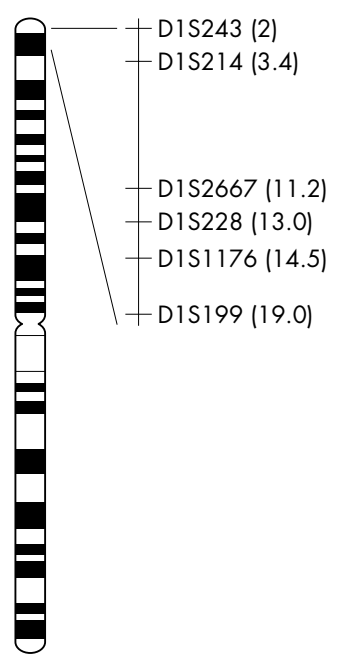

Figure 2 Physical position in megabases $(\mathrm{Mb})$ of the genetic markers across 1 ptel. Shaded boxes represent the critical regions from each congenital eye disease study. the $P A X 7$ gene inside the critical region defined by our study made it an excellent candidate gene. However, re-sequencing of the coding region of this gene in two of the affected patients from the Tasmanian family did not identify any mutations, apart from a common synonymous single nucleotide polymorphism (SNP) that has already been identified as a part of the human genome project (rs2743201) and therefore was very unlikely to have any influence on disease. While we cannot exclude that a mutation in a regulatory region of this gene may have a role, the absence of a coding region mutation suggests that the disease allele may lie in another gene within the critical region.

\section{DISCUSSION}

The linkage analysis results from the Tasmanian family clearly indicate the existence of a susceptibility gene at lp36. This is the third report of significant linkage in congenital cataract to the telomere of $1 \mathrm{p}$. Eiberg et $\mathrm{al}^{7}$ studied a large Danish pedigree affected with Volkmann-type cataract and mapped the predisposition gene for this disorder to the interval between the $1 \mathrm{p}$ telomere and D1S214. This region is $6 \mathrm{Mb}$ telomeric to the region defined by the recombinant individuals in the Tasmanian family. Both the Danish and our own results have reached highly significant linkage (Danish pedigree $\mathrm{LOD}=14.04$ Tasmanian pedigree $\mathrm{LOD}=$ 5.44) and with the physical positions better determined via the human genome project, we can determine that there is no ambiguity in the marker's position used by either study. The lack of overlap between the segregating haplotypes from the two studies makes it likely that the genes in the Tasmanian and Danish pedigrees are not allelic and there are two genes predisposing to congenital cataract on the telomere of $1 \mathrm{p}$.

The second report of linkage to this region was in a British family presenting with ADCC. ${ }^{8}$ Based on the haplotype in this British family, and particularly a homozygous stretch in a critical recombinant, the authors suggest that the gene segregating in this family might be allelic to the Danish Volkmann cataract pedigree. However, in reviewing the haplotype segregating in the British family in light of the region outlined here, we believe it also possible, if not more likely, that the gene in the British family could be allelic to the Tasmanian pedigree.

Interestingly, the critical region defined by the Tasmanian family also overlaps with that of the recessive primary congenital glaucoma locus, GLC3B..$^{20}$ Four of 13 patients from the Tasmanian family had aphakic glaucoma. This is relatively high for congenital cataracts, suggesting possible involvement of the same gene with both congenital glaucoma 
and cataract. However, the phenotypic differences between congenital cataract and congenital glaucoma, and genetic differences (a dominant versus recessive inheritance), make it equally likely that these disorders are not caused by the same gene. The mapping of the congenital cataract, congenital glaucoma and Volkmann-type cataract loci in this region indicates that the telomeric region of the $\mathrm{p}$ arm of chromosome 1 contains a number of genes that are relevant to both eye development as well as congenital eye disorders.

The physical distance defined as the critical region in the Tasmanian family is about $6 \mathrm{Mb}$. Inside this interval are 30 named genes, of which 18 are clearly noted to be expressed in the eye (www.ncbi.nlm.nih.gov/unigene). Also in this region are many more undescribed mRNAs and algorithm predicted genes. This makes the positional cloning of the causative gene a formidable task at this point. The identification of additional families linked to this region and containing informative recombinants may further restrict this region so that a positional cloning attempt is realistic. Identification of this gene and others that cause congenital cataract increases our understanding of the molecular events that lead to the development of cataract as well as the development of the eye.

\section{ACKNOWLEDGEMENTS}

This project would not have been possible without the financial support provided by the Ophthalmic Research Institute of Australia, the Jack Brockhoff Foundation, and the Royal Hobart Hospital Research Foundation and the National Health and Medical Research Council.

\section{Authors' affiliations}

J D McKay, B Patterson, J E Craig, K P Burdon, A W Hewitt,

D A Mackey, Menzies Centre for Population Health Research, University of Tasmania, Hobart, Australia

J D McKay, Genome analysis team, International Agency for Research on Cancer, Lyons, France

J E Craig, A C Cohn, Y Kerdraon, D A Mackey, Centre for Eye Research Australia, University of Melbourne, Royal Victorian Eye and Ear Hospital, Melbourne, Australia

J E Craig, Department of Ophthalmology, Flinders University, Flinders Drive, Bedford Park, South Australia

I M Russell-Eggitt, Great Ormond St Hospital for Children, London, UK M G Wirth, Department of Ophthalmology, Royal Children's Hospital, Melbourne, Australia

K P Burdon, Department of Biochemistry, Wake Forest University School of Medicine, Winston-Salem, NC, USA

Competing interests: none declared
Correspondence to: Associate Professor David Mackey, The Royal Victorian Eye and Ear Hospital, 32 Gisborne Street, East Melbourne, VIC 3002, Australia; d.mackey@utas.edu.au

\section{REFERENCES}

1 Litt M, Carrero-Valenzuela R, LaMorticella DM, et al. Autosomal dominant cerulean cataract is associated with a chain termination mutation in the human beta-crystallin gene CRYBB2. Hum Mol Genet 1997;6:665-8.

2 Pras E, Levy-Nissenbaum E, Bakhan T, et al. A missense mutation in the LIM2 gene is associated with autosomal recessive presenile cataract in an inbred Iraqi Jewish family. Am J Hum Genet 2002;70:1363-7.

3 Berry V, Francis P, Kaushal S, et al. Missense mutations in MIP underlie autosomal dominant 'polymorphic' and lamellar cataracts linked to 12q. Nat Genet 2000;25:15-7.

4 Conley YP, Erturk D, Keverline A, et al. A juvenile-onset, progressive cataract locus on chromosome $3 q 21-q 22$ is associated with a missense mutation in the beaded filament structural protein-2. Am J Hum Genet 2000;66:1426-31.

5 Semina EV, Ferrell RE, Mintz-Hittner HA, et al. A novel homeobox gene PITX3 is mutated in families with autosomal-dominant cataracts and ASMD. Nat Genet 1998;19:167-70.

6 Bu L, Jin Y, Shi Y, et al. Mutant DNA-binding domain of HSF4 is associated with autosomal dominant lamellar and Marner cataract. Nat Genet 2002;31:276-8.

7 Eiberg $\mathrm{H}$, Lund $\mathrm{AM}$, Warburg $M$, et al. Assignment of congenital cataract Volkmann type (CCV) to chromosome 1p36. Hum Genet 1995:96:33-8.

8 lonides AC, Berry V, Mackay DS, et al. A locus for autosomal dominant posterior polar cataract on chromosome 1p. Hum Mol Genet 1997;6:47-51. 9 Vanita, Singh JR, Sarhadi VK, et al. A novel form of "central pouchlike" cataract, with sutural opacities, maps to chromosome 15q21-22. Am J Hum Genet 2001;68:509-14.

10 Berry V, lonides AC, Moore AT, et al. A locus for autosomal dominant anterior polar cataract on chromosome 17p. Hum Mol Genet 1996;5:415-19.

11 Armitage MM, Kivlin JD, Ferrell RE. A progressive early onset cataract gene maps to human chromosome 17q24. Nat Genet 1995;9:37-40.

12 Yamada K, Tomita H, Yoshiura K, et al. An autosomal dominant posterior polar cataract locus maps to human chromosome 20p12-q12. Eur J Hum Genet 2000:8:535-9.

13 Wirth MG, Russell-Eggitt IM, Craig JE, et al. Aetiology of congenital and paediatric cataract in an Australian population. $\mathrm{Br} J$ Ophthalmol 2002;86:782-6.

14 Burdon KP, Wirth MG, Mackey DA, et al. Investigation of crystallin genes in familial cataract, and report of two disease associated mutations. Br J Ophthalmol 2004;88:79-83.

15 Sobel E, Lange K. Descent graphs in pedigree analysis: applications to haplotyping, location scores, and marker-sharing statistics. Am J Hum Genet 1996;58:1323-37.

16 O'Connell JR, Weeks DE. The VITESSE algorithm for rapid exact multilocus linkage analysis via genotype set-recoding and fuzzy inheritance. Nat Genet 1995; 11:402-8.

17 Kong A, Gudbjartsson DF, Sainz J, et al. A high-resolution recombination map of the human genome. Nat Genet 2002;31:241-7.

18 Broman KW, Murray JC, Sheffield VC, et al. Comprehensive human genetic maps: individual and sex-specific variation in recombination. Am J Hum Genet 1998;63:861-9.

19 Wolf MT, Lorenz B, Winterpacht A, et al. Ten novel mutations found in aniridia. Hum Mutat 1998;12:304-13.

20 Akarsu AN, Turacli ME, Aktan SG, et al. A second locus (GLC3B) for primary congenital glaucoma (buphthalmos) maps to the 1 p36 region. Hum Mol Genet 1996;5:1199-203. 